Article

\title{
Design and Analysis of a Next-Generation Wide Field-of-View Earth Radiation Budget Radiometer
}

\author{
Luca Schifano $1,2, * \mathbb{D}$, Lien Smeesters ${ }^{1,3}(\mathbb{D})$, Thomas Geernaert $1,3\left(\mathbb{D}\right.$, Francis Berghmans ${ }^{1,3}(\mathbb{D})$ and \\ Steven Dewitte ${ }^{2}$ \\ 1 Applied Physics and Photonics Department, Vrije Universiteit Brussel, Brussels Photonics (B-PHOT), \\ Pleinlaan 2, 1050 Brussels, Belgium; lsmeeste@b-phot.org (L.S.); tgeernae@b-phot.org (T.G.); \\ francis.berghmans@vub.be (F.B.) \\ 2 Royal Meteorological Institute of Belgium, Avenue Circulaire 3, 1180 Brussels, Belgium; \\ steven.dewitte@meteo.be \\ 3 Flanders Make, Pleinlaan 2, 1050 Brussels, Belgium \\ * Correspondence: luca.schifano@meteo.be
}

Received: 18 December 2019; Accepted: 24 January 2020; Published: 28 January 2020

\begin{abstract}
Climate on Earth is determined by the Earth Radiation Budget (ERB), which quantifies the incoming and outgoing radiative energy fluxes. The ERB can be monitored by non-scanning wide field-of-view radiometers, or by scanning narrow field-of-view radiometers. We propose an enhanced design for the wide field-of-view radiometer, with as key features the use of a near-spherical cavity to obtain a uniform angular sensitivity and the integration of the shuttered electrical substitution principle, eliminating long term drifts of the radiometer and improving its time response. The target absolute accuracy is $1 \mathrm{~W} / \mathrm{m}^{2}$ and the target stability is $0.1 \mathrm{~W} / \mathrm{m}^{2}$ per decade for the measurement of the total outgoing Earth's radiation. In order to increase the spatial resolution and to separate the total outgoing radiation into reflected Solar and emitted thermal radiation, we propose the joint use of the radiometer with wide field-of-view Shortwave $(400-900 \mathrm{~nm})$ and Longwave $(8-14 \mu \mathrm{m})$ cameras. This paper presents the concept and design of the novel wide field-of-view radiometer, including simulations and analyses of its expected performance. We focus on mechanical design and the measurement characteristics based on optical and thermal analyses. In combination with the cameras, we obtain an estimated accuracy of $0.44 \mathrm{~W} / \mathrm{m}^{2}$.
\end{abstract}

Keywords: Earth Radiation Budget; Earth Energy Imbalance; space instrumentation; radiometer; optical modelling; thermal modelling

\section{Introduction}

Climate on Earth is determined by the radiative energy fluxes at the Earth's top of atmosphere (TOA) [1]. The Earth Radiation Budget (ERB) quantifies the incoming and outgoing radiative energy fluxes at the TOA. These radiative fluxes are the Incoming Solar Radiation (ISR) or the so-called Total Solar Irradiance (TSI), the Reflected Solar Radiation (RSR), and the radiative flux emitted by the Earth, or the so-called Outgoing Longwave Radiation (OLR). Due to their fundamental importance for climate change, the ERB components are part of the Essential Climate Variables (ECV's), of which the monitoring is mandatory following the World Meteorological Organization (WMO) Global Climate Observing System (GCOS) requirements [2]. The Earth Energy Imbalance (EEI), more particularly, is among the most fundamental climate change parameters to be monitored [3-5]. The EEI is the small but non-zero difference between Earth's incoming and outgoing radiative energy fluxes:

$\mathrm{EEI}=\mathrm{ISR}-\mathrm{RSR}-\mathrm{OLR}$; it is the direct driver of climate change on Earth.

ERB can be monitored in two different ways: in situ ocean measurements or space-based measurements. In situ ocean measurements from the Argo network [6] have reached the state-of-the-art 
accuracy of $\pm 0.3 \mathrm{~W} / \mathrm{m}^{2}$ on the EEI [7]. However, since these measurements are averaged over at least one decade, they contain large sampling uncertainties at shorter timescales and are therefore not suited for short-term climate monitoring [8]. Next to the in situ ocean measurements, broadband satellite observations of the ERB are another well-established scientific method to evaluate EEI values [9]. This involves the measurement of both the TSI and the global Earth total outgoing radiation (TOR), determined by the sum of the Earth's shortwave (SW) and longwave (LW) radiation (Figure 1). In comparison to the in situ ocean measurements, these satellite observations show a higher stability of a few tenths of a $\mathrm{W} / \mathrm{m}^{2}$ per decade, while providing more accurate sampling [10].

Currently, the ERB monitoring relies on NASA's CERES program, which uses two complementary orbits for the sampling of the diurnal cycle [11]. The first orbit is the so-called morning orbit, with Local Time of Descending Node (LTDN) around 10:00 a.m. This orbit is covered by the two CERES instruments on the Terra satellite, with an expected end of life in 2026. The second orbit, the so-called afternoon orbit with Local Time of Ascending Node (LTAN) around 2:00 p.m., is covered by multiple CERES instruments on Aqua, Suomi NPP and NOAA-20, and is also expected to be continued by the CERES Earth Venture Continuity follow-on program [11]. Each CERES instrument is composed of a scanning radiometer, measuring the ERB in three spectral ranges: total $(0.3-200 \mu \mathrm{m})$, window $(8-12 \mu \mathrm{m})$ and shortwave $(0.3-4 \mu \mathrm{m})$ [12]. NASA used to measure the ERB using non-scanning wide field-of-view (WFOV) radiometers during the Nimbus 6, Nimbus 7 and ERBE missions [1]. During the Earth Radiation Budget Experiment (ERBE) mission [13], the low-resolution ERB measurements obtained using WFOV radiometers were compared with the higher resolution measurements from the scanning radiometers. The latter provided measurements with a better spatial resolution and avoided the thermal offset problems of WFOV radiometers [8]. Hence the CERES program continued with scanning radiometers [11,12].

However, no measurement technique has yet reached the absolute accuracy of $1 \mathrm{~W} / \mathrm{m}^{2}$ required to make significant measurements of the EEI. Alternative observation methods to determine the EEI have been summarised by Wong et al. [8], but have not demonstrated sufficient accuracy either [4]. For all these reasons, and considering advances in instrument technology and the availability of small satellite platforms [8], the determination of the EEI using broadband non-scanning WFOV instruments has recently received a renewed interest. The target stability that has been adopted for the CERES radiometers is $0.3 \mathrm{~W} / \mathrm{m}^{2}$ per decade [14]. Stability is easier to achieve than absolute accuracy, and is more relevant for climate change monitoring. In [5], changes of the EEI of the order of $0.1 \mathrm{~W} / \mathrm{m}^{2}$ per decade are reported, and the absolute accuracy of CERES in the EEI measurement equals $4.9 \mathrm{~W} / \mathrm{m}^{2}$, which is the state-of-the-art accuracy.

We target the development of a novel instrument that aims to continue and improve on ERB monitoring, using:

- a WFOV radiometer-equipped with a shutter to avoid the thermal offset problem-measuring the TOR spectrally integrated over the $0.3-100 \mu \mathrm{m}$ band. The radiometer aims to provide reference measurements of the TOR with an accuracy of $1 \mathrm{~W} / \mathrm{m}^{2}$ and a stability of $0.1 \mathrm{~W} / \mathrm{m}^{2}$ per decade. The of the radiometer will be of the order of $6000 \mathrm{~km}$.

- a WFOV SW camera measuring visible light integrated over the $400-900 \mathrm{~nm}$ spectral band. The SW camera-calibrated by the radiometer-aims to provide measurements of the RSR with a spatial resolution of the order of $10 \mathrm{~km}$.

- a WFOV LW camera measuring thermal infrared light integrated over the 8-14 $\mu \mathrm{m}$ spectral band. The LW camera-calibrated by the radiometer-aims to provide measurements of the OLR with a spatial resolution of the order of $10 \mathrm{~km}$.

This paper focuses on the design and simulated performance of the WFOV radiometer. It is structured as follows. Section 2 discusses the design method and radiometer constraints. Section 3 gives an overview of its performance, including the spatial non-uniformity of the temperature inside the cavity radiometer, the solution to the thermal offset issue using shuttered operation, and an 
estimation of the error budget. Section 4 summarises our findings, and anticipates on the future development of a radiometer prototype and on the inclusion of the SW and LW cameras.

\section{Instrument Design}

Accurately monitoring the ERB with the radiometer involves the measurement of radiative power using the electrical substitution principle. To push the radiometer performance, and in view of achieving thermal equilibrium efficiently, we implement an electronic servo system. This methodology has been successfully used since 1983 by the Royal Meteorological Institute of Belgium (RMIB) for TSI measurements [15]. While TSI is measured by using absolute radiometers with a narrow FOV to observe the Sun, a WFOV is required to observe the Earth, as illustrated in Figure 1. Several WFOV radiometer designs have already been developed, e.g., the RAVAN CubeSat [16] by the Johns Hopkins University Applied Physics Laboratory, or the SIMBA CubeSat $[17,18]$ by RMIB.

Narrow field-of-view radiance measurements collect the radiation in a single direction and require the use of Angular Dependency Models (ADMs) to estimate the radiative flux at the TOA [19]. These ADMs are a dominant error source for such narrow field-of-view ERB instruments, and should be avoided when better accuracy is aimed for. Consequently, to improve the accuracy, we focus on the use of a wide field-of-view observation, where the radiative flux at satellite altitude is measured by integrating the Earth's radiation observed from limb to limb. From a nominal satellite altitude of $700 \mathrm{~km}$, this requires an FOV of $127^{\circ}$. In order to allow for pointing errors, we consider a slightly larger FOV of $135^{\circ}$ for the unobstructed radiometer.

To avoid calibration errors while measuring the EEI, we propose to measure the incoming Solar radiation (the TSI), the reflected Solar radiation and the radiative flux emitted by the Earth at the TOA with the same radiometer, as shown in Figure 1. The radiometer will be nominally nadir-pointing to observe the radiative flux emitted and reflected by the Earth, while Solar pointing will be used occasionally for Solar calibration, enabling a differential measurement of the EEI [20]. Since the TSI variation is well-known from operational TSI radiometers [21], it does not need to be monitored continuously.

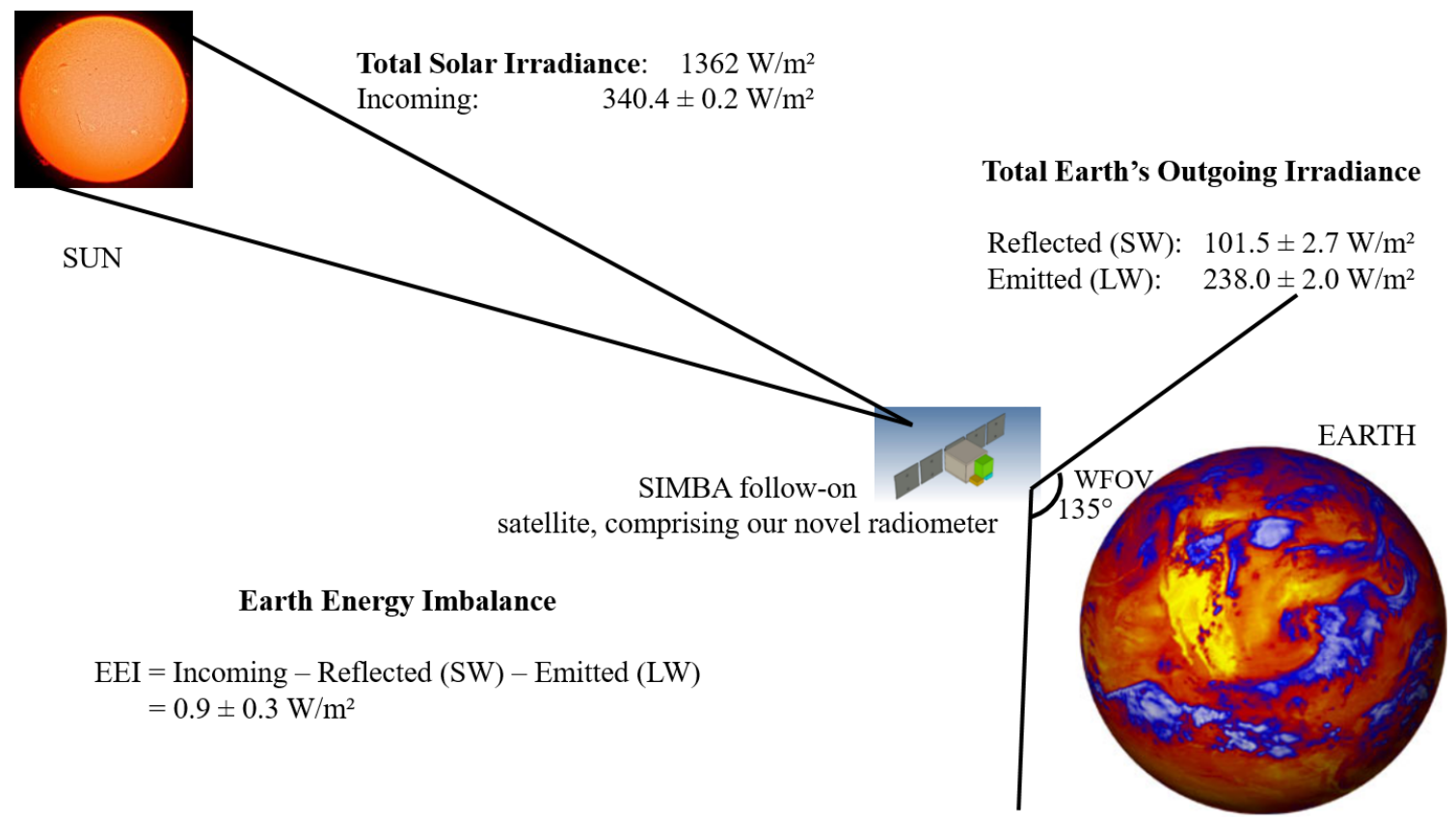

Figure 1. Earth viewed by the wide field-of-view (WFOV) radiometer. Occasional Solar pointing will allow intercalibrating the Incoming Solar Radiation and the Earth's Total Outgoing Radiation measurements. SW stands for shortwave and LW for longwave. Values for the irradiances are derived from [1]. 
To achieve enhanced performance of the radiometer, its design is improved by combining: (1) a novel cavity shape, (2) a precision aperture, (3) a servo system, (4) a dual-channel radiometer design with (5) a shutter in front of each cavity. The latter is used to avoid the thermal offset problem encountered in WFOV radiometers. The radiometer consists of two WFOV cavities, both operating over the total spectrum, to achieve high stability: one cavity measures continuously and is possibly aging due to exposure to Solar UV radiation, whilst the second cavity is exposed infrequently and allows assessing and correcting for the aging of the measurement cavity.

Inside the cavity radiometer, the collected optical power is transformed into heat through absorption by a black material. The absorption factor is enhanced geometrically through multiple reflections in a hollow volume-called a cavity-yielding an active absorption factor that is close to unity. The radiation to be measured enters the cavity through a small opening with a known area, called the precision aperture.

The radiometer is equipped with a shutter, which can be opened and closed with a rotary actuator. The radiative power is measured using the electrical substitution principle [22]. In a shuttered electrical substitution radiometer, the absorbed optical power is measured by comparing the generated heat with a known electrical power which has the same thermal effect. A shutter sequentially opens and closes, allowing optical power to enter the cavity in the open state, and blocking it in the closed state. The electrical power is regulated by a servo system maintaining the cavity at a constant temperature. The change of electrical power between the opened and closed states is a differential measurement of the optical power in the opened state. This operation mode is generally used in TSI radiometers, and is expected to eliminate the thermal offset problem encountered in existing wide field-of-view radiometers. Shuttered operation enables to eliminate long term drifts at time scales longer than the shutter period.

\subsection{Radiometer Thermo-Mechanical Design}

The mechanical design of our novel ERB WFOV radiometer is presented in Figure 2. The Solar and Earth's radiations enter the cavity through a precision aperture, positioned at the bottom of the radiometer. The incoming radiation, entering the precision aperture within the FOV angle of $135^{\circ}$, falls onto the spherical top part of the cavity. For any angle of incidence, the distance between the aperture and the sphere is constant, and equal to $25 \mathrm{~mm}$, which is beneficial to the angular uniformity of the radiometer sensitivity [23]. Radiation reflected from the top spherical part is mostly absorbed by the conical part, while only a minor part can escape through the cavity aperture.

To ensure an absorbance of the radiation close to $100 \%$, the cavity parts are coated with a black material, absorbing nearly all incoming radiation from ultraviolet (UV) to far-infrared (FIR). After having absorbed this radiation, the latter is converted into heat inside the cavity. Two coating materials will be considered: Black Velvet and Vantablack. Black Velvet, also known as Nextel 811-21 [24,25], has a nominal absorbance of $97 \%$ for normal incidence, in both the short wavelength range (mainly in visible) and in the long-wavelength range (mainly thermal infrared) [24]. This coating has shown a good absorbing performance in previous RMIB TSI radiometers [21]. Vantablack features a higher absorbance. However, this coating uses Vacuum Aligned Carbon Nanotubes (VACNT) technology, and may suffer from defects occurring during the depositing process [26]. We will compare the performance of both coatings in Section 3.2.

With a spacing between the spherical and conical part of the cavity, no heat transfer by conduction between those parts is allowed, and they are thermally disconnected. Both parts have their own temperature measurements, electrical heaters, and servo systems, and will be used as an electrical substitution detector, where the electrical power is regulated such that the part temperature remains constant. The radiative power experienced by the conical part allows us to monitor the radiation reflected by the spherical part. The outer side of the cavity parts are thermally insulated and covered with low emissivity coating in order to minimize the radiative energy exchange with the cavity 
surrounding, similar to [27]. The cavity surrounding are kept at a constant temperature (293.15 K), by a dedicated servo system.

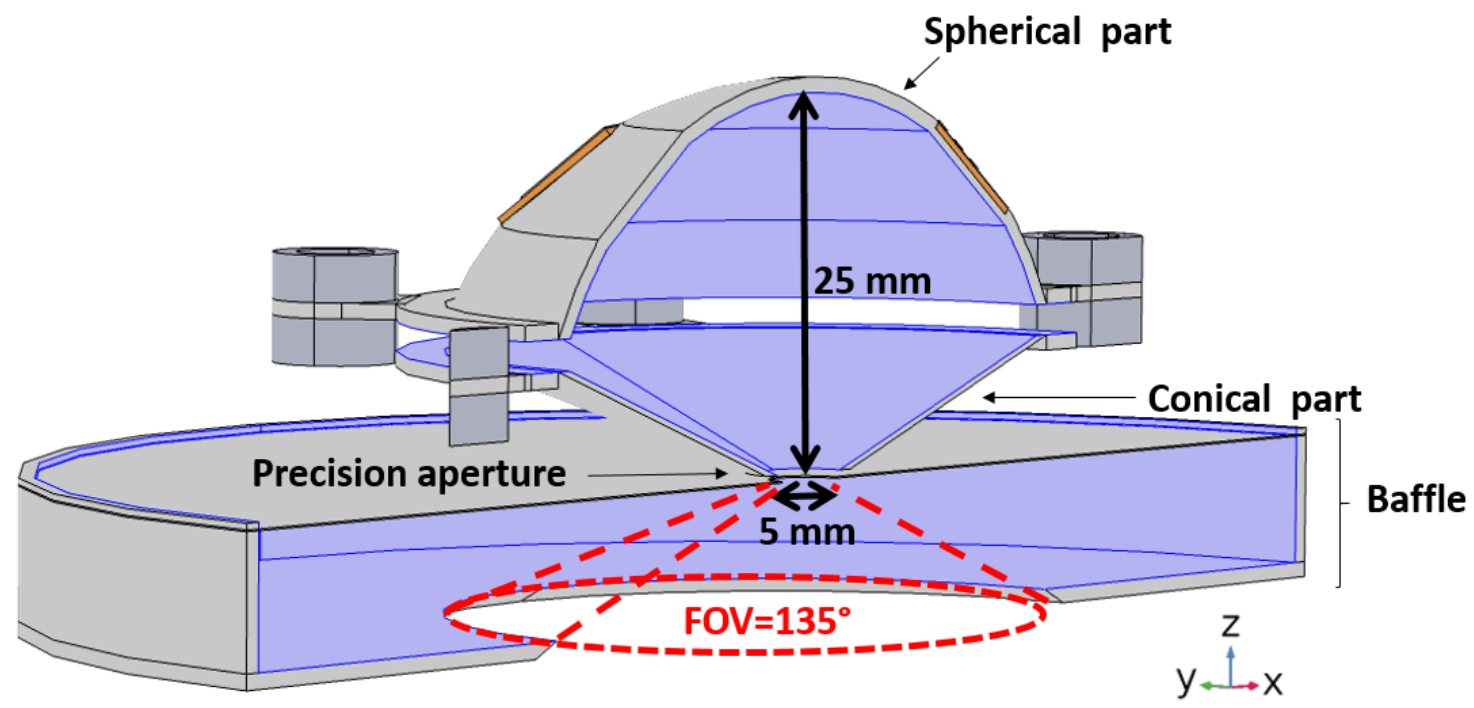

Figure 2. 3D view of a section of the radiometer. The cavity is composed of a spherical part and a conical part. The precision aperture and baffle limit the field-of-view (FOV) to $135^{\circ}$.

\subsection{Digital Servo Electronics and Algorithm}

The radiometer is equipped with a servo system that is used for:

- $\quad$ implementing the electrical substitution principle ;

- $\quad$ increasing the system time response, by adapting the gain of the servo system.

A digital servo algorithm is implemented in a microprocessor, which is connected by Serial Peripheral Interfaces (SPIs) to a Digital to Analog Convertor (DAC) and a 24-bit Analog to Digital Convertor (ADC), whose sampling time is faster than 1 second (Figure 3). The ADC digitalizes the temperature $T$ to be regulated, the voltage $V$ over the heating resistance $R_{h}$, and the current $I$ trough the heating resistance. The current $I$ is measured by placing a measurement resistor $R_{m}$ in series with $R_{h}$, and by measuring the voltage $R_{m} * I$. The electrical heater power is determined as $P_{e l}=V * I$. The temperature $T$ is measured by way of the voltage $V(T)$ over a thermistor with resistance $R(T)$, which forms a voltage divider with a reference resistor $R_{r e f}$.

The electrical substitution is implemented by regulating the total electrical power $P_{e l}$ in the heating resistors such that a chosen temperature for the spherical part of the cavity, $T_{c}$, has a certain offset $\Delta T=T_{c}-T_{h}$ compared to the housing temperature $T_{h}$.

In first approximation, the cavity behaves as a first-order thermal system with time constant $\tau=R_{t h} * C_{t h}$ (in s), where $R_{t h}$ (in $\mathrm{K} / \mathrm{W}$ ) is the total thermal resistance between the cavity and the housing, and $C_{t h}$ (in $\mathrm{J} / \mathrm{K}$ ) is the thermal capacity of the cavity. The cavity is heated by a total power $P_{\text {opt }}+P_{e l}$, with $P_{\text {opt }}$ the optical (radiative) power.

In Laplace transform notation we can write:

$$
\Delta T(s)=\frac{P_{e l}(s)+P_{o p t}(s)}{R_{t h}} \frac{1}{1+s \tau} .
$$

with $s$ the Laplace variable.

The microprocessor, in which the digital servo algorithm is implemented, regulates the applied electrical power $P_{e l}$, such that $\Delta T(s)$ reaches a set point $\Delta T_{s e t}$. By default, the servo algorithm will be a Proportional Integral (PI) algorithm described by 


$$
\frac{P_{e l}(s)}{R_{t h}}=\left(K_{p}+\frac{K_{i}}{s}\right)\left(\Delta T_{s e t}-\Delta T(s)\right),
$$

where $K_{p}$ is the servo proportional gain and $K_{i}$ is the servo integral gain.

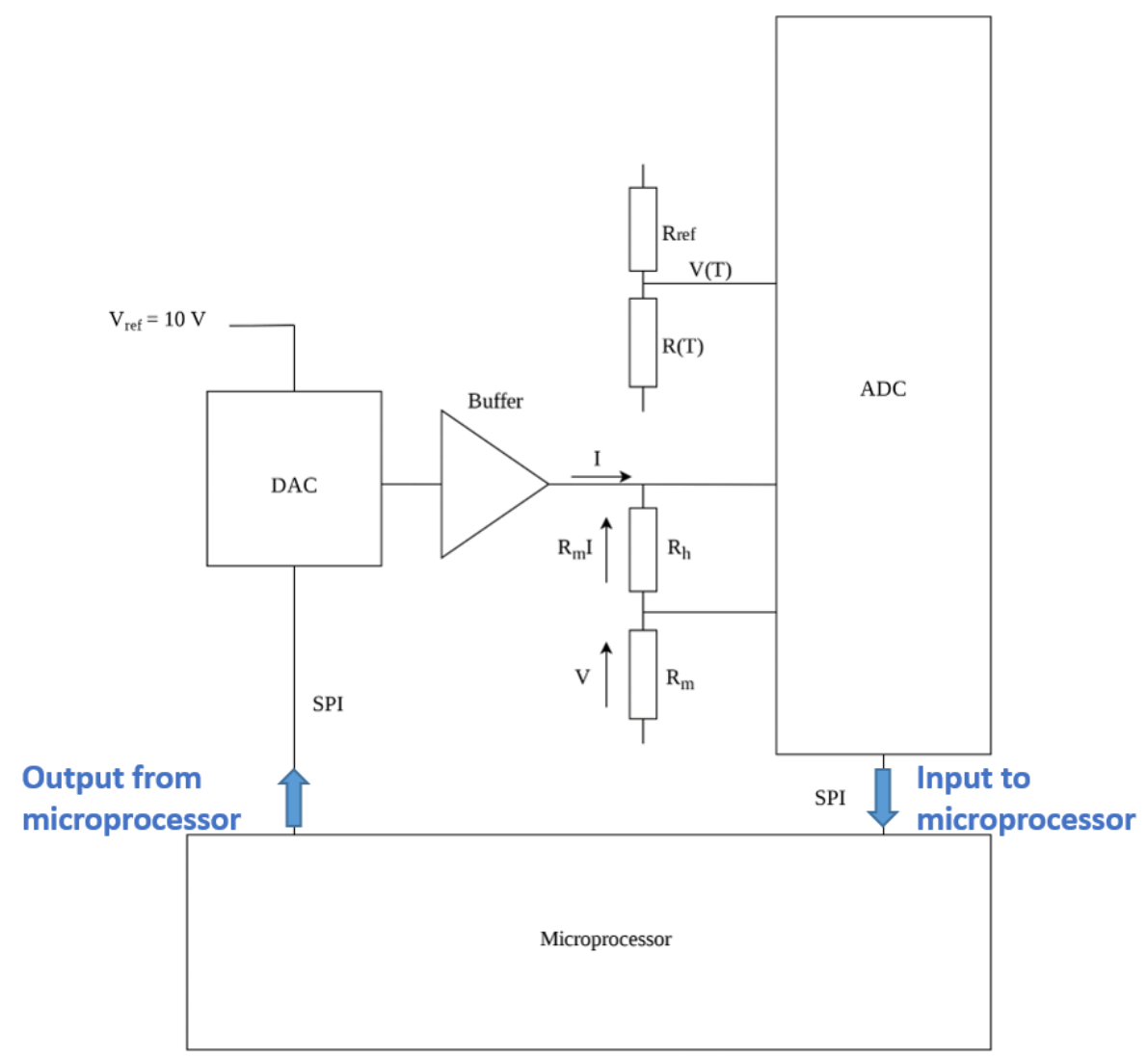

Figure 3. Scheme of the electronics of the radiometer servo system.

The resulting open-loop gain $G_{o l}(s)$ is given by

$$
G_{o l}(s)=\frac{1}{1+s \tau}\left(K_{p}+\frac{K_{i}}{s}\right) .
$$

The thermal constant $\tau$, which is expected to be high since it characterizes the slow heating of the cavity, can be compensated by choosing $K_{i}=K_{p} / \tau$. In that case, the open-loop gain $G_{o l}(s)$ simplifies [28] to

$$
G_{o l}(s)=\frac{K_{p}}{s \tau} .
$$

The total regulated system, consisting of the physical system and the digital servo, will react with an equivalent time constant of $\tau / K_{p}$, which is accelerated by a factor $K_{p}$ compared to the physical system.

\subsection{Synergy of Radiometer with Cameras}

The detailed outlook of the narrowband WFOV cameras mentioned in the introduction will be similar to [29] and will be described in future papers. However, we include a brief outline of how the cameras will be used in synergy with the radiometers.

The narrowband WFOV cameras give estimates of the broadband longwave radiance $L_{L W}^{e s t}(x, y)$ and shortwave radiance $L_{S W}^{e s t}(x, y)$ for every camera pixel $(x, y)$, using radiative transfer based narrowband to broadband conversion. The typical accuracy of $L_{L W}^{e s t}(x, y)$ and $L_{S W}^{e s t}(x, y)$ is $5 \%$. These broadband radiances will be integrated over the radiometer footprint to obtain estimates 
of the LW contribution $F_{L W}^{e s t}(W F O V)$ and the SW contribution $F_{S W}^{e s t}(W F O V)$ to the radiative flux at the satellite level $F(W F O V)=F_{L W}(W F O V)+F_{S W}(W F O V)$ as measured by the radiometer. An LW calibration factor $k_{L W}$ and an SW calibration factor $k_{S W}$ will be derived from separate calibrations during night and day:

$$
\begin{aligned}
& \text { night: } F_{S W}(W F O V)=0, k_{L W}=F(W F O V) / F_{L W}^{e s t}(W F O V) \\
& \text { day: } k_{S W}=\left(F(W F O V)-k_{L W} F_{L W}^{e s t}(W F O V)\right) / F_{S W}^{e s t}(W F O V) .
\end{aligned}
$$

The application of the calibration factors in general conditions will yield the calibrated LW radiance $L_{L W}(x, y)=k_{L W} L_{L W}^{e s t}(x, y)$ and the calibrated SW radiance $L_{S W}(x, y)=k_{S W} L_{S W}^{e s t}(x, y)$.

Considering the assessment of the spatial non-uniformity of the optical heating of the radiometer, $L_{T O T}^{\text {est }}(x, y)=L_{L W}^{\text {est }}(x, y)+L_{S W}^{\text {est }}(x, y)$ will be used as an estimate of the total radiance $L_{T O T}(x, y)=L_{L W}(x, y)+L_{S W}(x, y)$.

\subsection{Note on the Spatial Non-Uniformity}

The cavity temperature shows a spatial non-uniform behavior, since the conductive heat flow in the cavity side-wall causes a thermal gradient. In case this spatial thermal non-uniformity is not properly accounted for, it will create a systematic variation of the sensitivity of the cavity with the angle of incidence of the incoming optical power. The total sensitivity of the cavity equals the integral of the product of the local sensitivity multiplied with the normalized spatial distribution of the absorbed power. If we consider a localised optical power $P_{o p t}(x, y)$ incident at point $(x, y)$, it will be measured by a closed minus open electrical power difference $\Delta P_{e l}(x, y)$. We define the local sensitivity $s(x, y)$ as $\Delta P_{e l}(x, y) / P_{o p t}(x, y)$. The total sensitivity is the spatial integral of the local sensitivity multiplied with the normalized spatial distribution of $P_{o p t}$. These two quantities, total sensitivity, and local sensitivity, are without units.

Multiple measures will be taken to reduce the error on the measurement of $P_{o p t}$, caused by the spatial non-uniformity of the cavity:

- The spherical part of the cavity will be equipped with a temperature measurement at its top $\left(T_{\text {top }}\right)$ and side $\left(T_{\text {side }}\right)$, allowing to quantify the thermal gradient in the cavity.

- The heating resistor will be located such that for a given power it creates the same thermal difference $T_{\text {top }}-T_{\text {side }}$ as the average spatial distribution of the incoming optical power. This incoming optical power corresponding to the Earth's radiation is considered to be emitted by a Lambertian source.

- Prior to launch, the actual local sensitivity of the cavity will be characterized by scanning it with a stabilized laser beam.

- $\quad$ During flight, the spatial distribution of $P_{o p t}$ will be quantified by the wide field-of-view cameras. Knowledge of the distribution of the optical power measured during flight and the local sensitivity measured prior to flight allows calculating the factor required to correct for the thermal non-equivalence of optical and electrical heating.

\section{Results}

This section provides an evaluation of the radiometer performance. First, we detail the mechanical design. Second, we calculate the radiometer cavity absorbance, taking into account the geometry of the cavity. From this study, we derive the cavity absorption factors for different coatings and different illumination cases. Third, we simulate the stationary thermal distribution inside the cavity for different heating cases and we assess the thermal non-uniformity. Fourth, we simulate the dynamic performance of the radiometer based on the servo system and the shuttered operation. Finally, we calculate the error budget, taking into account the different error sources. 


\subsection{Detailed Radiometer Design}

As introduced in Section 2.1, the radiometer comprises different heat sinks and electrical resistors, in combination with a precision aperture. In order to monitor the total Earth's radiative flux from space, the radiometer requires a large FOV of $135^{\circ}$, which is defined by the baffle below the cavity. The cavity is composed of a conical part with the same top-angle as the FOV, and a spherical part, to ensure an angularly uniform illumination inside the cavity. To avoid heat transfer by conduction between the spherical and conical parts of the cavity, these two parts are separated by a spacing. Each part is coated on the inside, allowing the radiative energy to be absorbed and measured by the radiometer. There is no heat transfer by convection, nor by conduction, between the spherical and conical parts. The only possible heat transfer between these parts is by radiation. The cavity is put in the housing at a constant temperature of $293.15 \mathrm{~K}$. Each part is cooled by three thermal sinks to ensure a symmetrical and constant temperature gradient. On the outside of the spherical part, three electrical resistors are placed symmetrically to allow heating up of the cavity and implementing the electrical substitution principle. Each electrical resistance is placed on the outside of the cavity halfway in-between the cavity top and each of the three thermal sinks. The details of the radiometer assembly are shown in Figure 4.
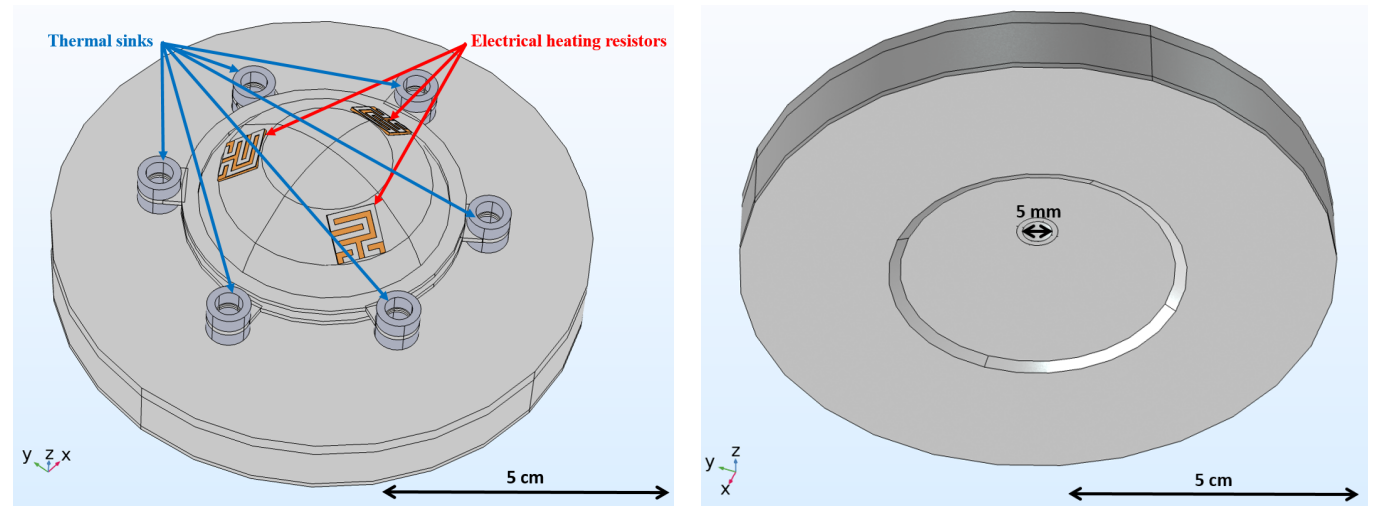

Figure 4. Cavity radiometer, with a $5 \mathrm{~mm}$ diameter circular precision aperture, viewed from the top (left) and bottom (right). The cavity is in Aluminium, thermal sinks are made of Permaglas ${ }^{\circledR}$, and electrical heating resistors are modeled as a Constantan wire on a Polyimide layer.

\subsection{Cavity Absorbance}

We define the cavity absorbance as the part of the radiation entering the precision aperture that is absorbed within the cavity and subsequently measured with an electrical substitution detector. The radiation that is not measured is (1) the reflected radiation that escapes through the precision aperture, and (2) the reflected radiation that is absorbed by the backside of the precision aperture. The cavity absorbance depends on the angular distribution of the measured radiation and on the spectral absorbance of the material used to coat the inside of the cavity. We consider two types of absorbing materials: Black Velvet and Vantablack, with spectral absorbance given in Table 1 . We also consider three illumination cases: SW Earth (400-900 nm), LW Earth (8-14 $\mu \mathrm{m})$ and Solar, of which the characteristics are given in Table 2.

Table 1. Spectral absorbance and uncertainty of Black Velvet and Vantablack. For perpendicular illumination, the absorbance values for LW and SW are equal within the uncertainty.

\begin{tabular}{ccc}
\hline & Black Velvet [24] & Vantablack $[30,31]$ \\
\hline LW & $0.97+/-0.01$ & $0.998+/-0.001$ \\
SW & $0.97+/-0.01$ & $0.999+/-0.001$ \\
\hline
\end{tabular}


Table 2. Illumination cases.

\begin{tabular}{cc}
\hline & Angular characteristics \\
\hline LW Earth & Lambertian source 127 \\
SW Earth & Lambertian source 127 \\
Solar & Incidence angle $=0^{\circ}$ \\
\hline
\end{tabular}

The cavity absorbance for each of the illumination cases, when considering the different coating absorbances, can be calculated using the view factors from [32,33]. The results are given in Table 3.

Table 3. Calcultated cavity absorbance with Black Velvet and Vantablack, when measuring Earth's SW radiation, Earth's LW radiation, and Solar calibration.

\begin{tabular}{ccc}
\hline & Black Velvet & Vantablack \\
\hline LW Earth & $0.99985+/-0.00005$ & $0.99999+/-0.00001$ \\
SW Earth & $0.99985+/-0.00005$ & $0.999995+/-0.000005$ \\
Solar & $0.99980+/-0.00007$ & $0.999993+/-0.000007$ \\
\hline
\end{tabular}

The Vantablack coating shows a higher absorbance than Black Velvet. However, the impact on the final accuracy of the radiometer is negligible. Considering the drawbacks associated with Vantablack (cost, deposition technique), Black Velvet is preferred.

\subsection{Thermal Analysis}

The optical power entering the cavity radiometer is measured by comparing it to an equivalent electrical power, through the operation of the servo system, as also introduced in Section 2.

The optical and electrical powers induce different thermal gradients in the cavity. We simulated these gradients with COMSOL Multiphysics [34,35], using the cavity radiometer geometry as illustrated in Figure 4. To do so, a physics-controlled mesh with default size is applied to this geometry (Figure 5).

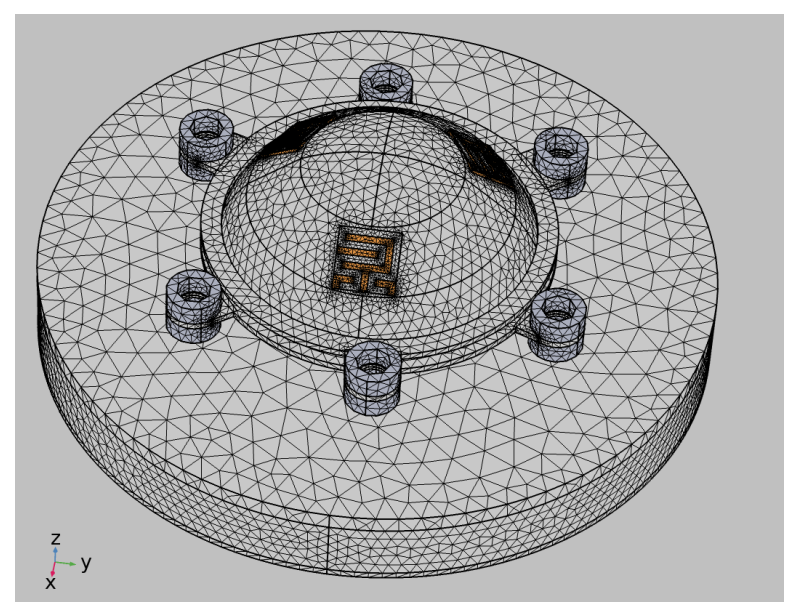

Figure 5. Mesh used in our COMSOL simulations.

Table 4 gives the thermal conductivity for each of the materials that are used in our simulations. Most of the radiometer is in Aluminium whose specific heat capacity is $904 \mathrm{~J} /(\mathrm{kg} \mathrm{K})$. However, thermal heat sinks are made of Permaglas ${ }^{\circledR}$, and the electrical heating resistors are modeled as a Constantan wire on a Polyimide layer. In our simulations, COMSOL's Heat Transfer in Solids module is used to simulate heat transfer by conduction. All boundaries, including the exterior surfaces of the cavity, are thermally insulated, except for the edges of each thermal sink, where a constant temperature of 293.15 K is applied. The optical heating is simulated using the deposited beam power feature, passing through the precision aperture and reaching the spherical top at the inside of the cavity. The electrical 
heating is simulated using a heat flux, in particular, the heat rate feature, applying a power distribution between each electrical heater.

Table 4. Thermal conductivity for the materials that are used in our simulations.

\begin{tabular}{ccccc}
\hline & Aluminium & Permaglas ${ }^{\circledR}[36]$ & Polyimide & Constantan \\
\hline Thermal conductivity $[\mathrm{W} /(\mathrm{m} . \mathrm{K})]$ & 237 & 0.35 & 0.15 & 19.5 \\
\hline
\end{tabular}

Simulations of the temperature difference between the cavity and the housing, and of the temperature distribution within the cavity, are made for different spatial distributions of the applied heating. Because the optical heating is non-uniform, we simulated the temperature distribution inside the cavity to assess the spatial non-uniformity. In the end, we compare the optical and electrical heating in case of Earth observation and Solar calibration. To measure the cavity temperature, which serves as input for the servo system, we need to install thermistors at the most adequate locations. Therefore, thermistors will be nominally placed on the top of the cavity, and at each thermal sink, where we expect maximal and minimal temperatures, respectively.

\subsubsection{Simulating Solar Radiation}

In the case of optical heating by the Sun, the Solar radiation is simulated as a top-hat disk beam, since we expect to have parallel rays for the incoming Solar radiation [34]. This assumes a uniform Solar radiation intensity that becomes a circular beam once that radiation has passed through the circular aperture of the instrument. The beam radius equals the size of the precision aperture $(\mathrm{R}=2.5 \mathrm{~mm})$. The beam optical power equals $27 \mathrm{~mW}$, corresponding to $1362 \mathrm{~W} / \mathrm{m}^{2}$ of Solar irradiance (Figure 1), entering the cavity through a precision aperture of $5 \mathrm{~mm}$ diameter. Figure 6 (left) shows the corresponding 3D temperature distribution inside the cavity, obtained by optical heating. Figure 6 (right) shows the 3D temperature distribution for an electrical heating with the same power of $27 \mathrm{~mW}$. In these figures, we show the temperature elevation in $\mathrm{mK}$, with respect to an initial temperature of $293.15 \mathrm{~K}$.
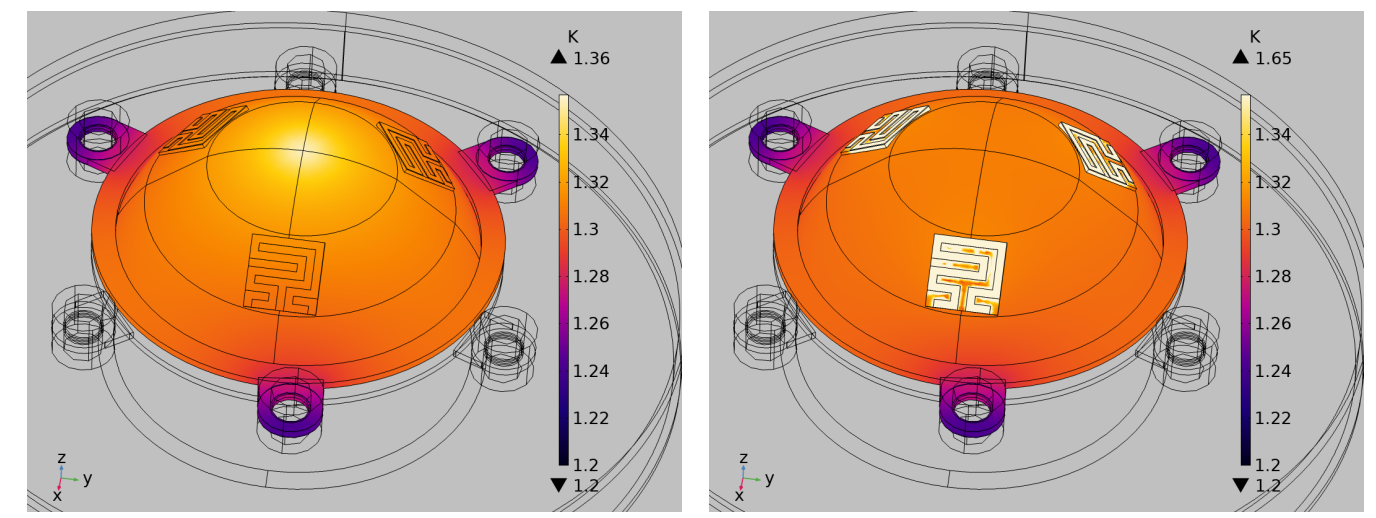

Figure 6. Temperature distribution inside the cavity, resulting from simulated Solar radiation (left) and from electrical heating (right), with the same power of $27 \mathrm{~mW}$.

Since the temperature distribution is symmetrical, we are particularly interested in the temperature profiles along the spherical part of the cavity while passing through the top (Figure 7, left), and along the edge of the spherical part while passing by the three thermal sinks (Figure 8, left), where the thermistors are positioned. 

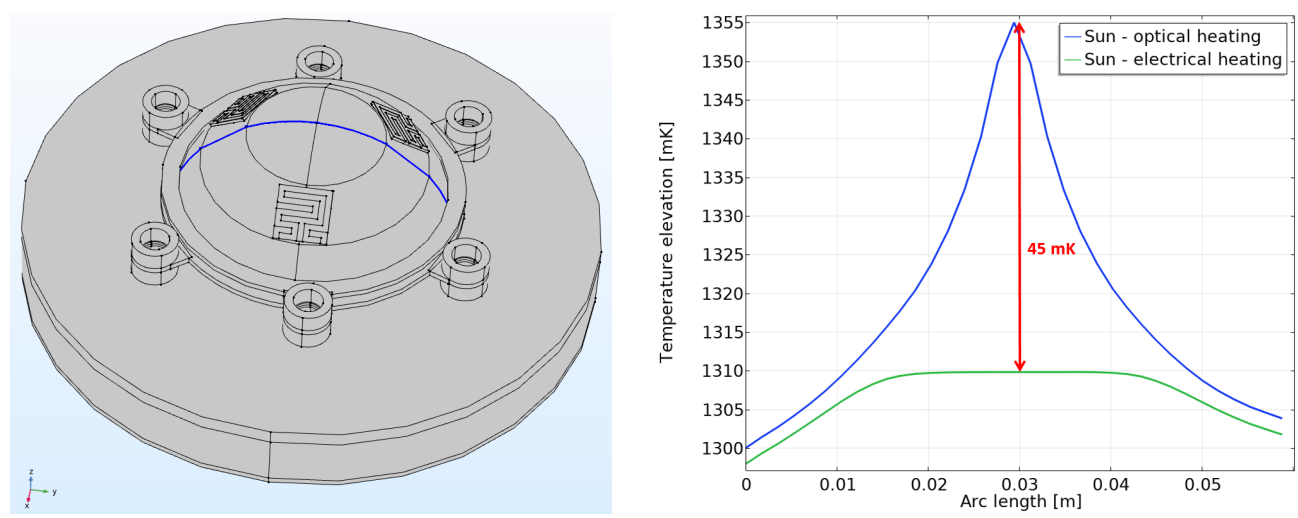

Figure 7. We analyse the temperature elevation along the blue curve that follows the spherical part of the cavity, passing through the top of the cavity (left). The graph (right) shows the temperature distribution along this curve, for both optical and electrical heating.
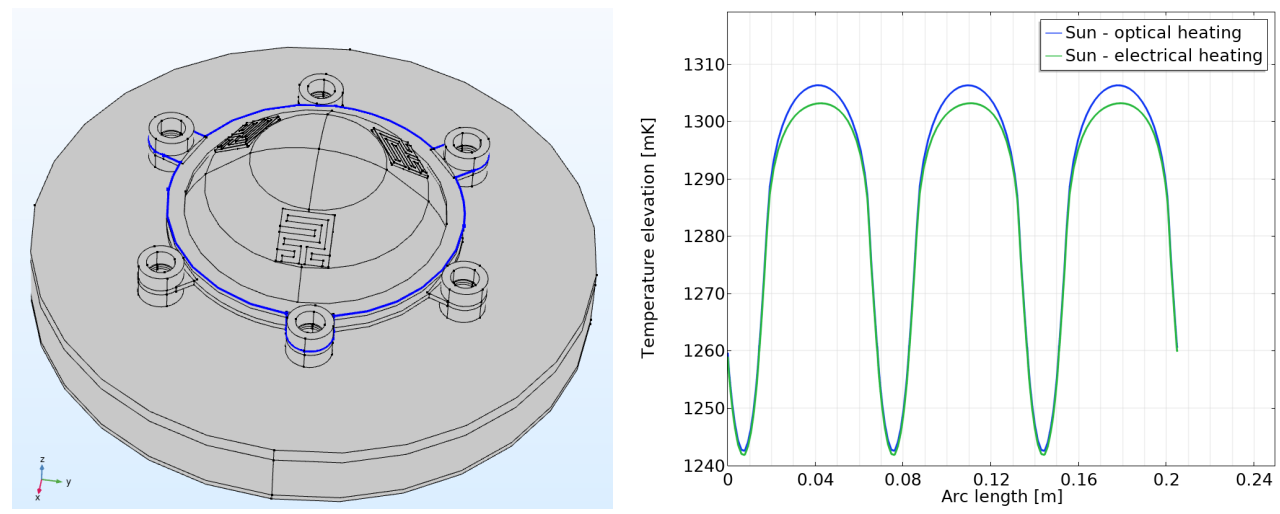

Figure 8. We analyse the temperature elevation along the blue curve that follows the edge of the spherical part of the cavity, passing by the three heat sinks of the cavity (left). The graph (right) shows the temperature distribution along this curve, for both optical and electrical heating.

Figures 7 (right) and 8 (right) show a comparison between the simulated temperature for optical and electrical heating along the top of the spherical part of the cavity, and along the three thermal sinks attached to the spherical part of the cavity, respectively. Since a trade-off for the numbers of electrical heaters needed to be made, we found that using three electrical heaters, with a total electrical power of $27 \mathrm{~mW}$ distributed over these three electrical heaters, tends to best approximate optical heating of the same total power. The use of fewer electrical heaters is insufficient to obtain a good approximation of the heating by the incoming optical power, while the use of more electrical heaters would impose a more difficult practical implementation.

When using COMSOL's Surface-to-Surface Radiation module [37], blackbody radiation is taken into account inside the cavity. This module computes the view factors that were discussed in Section 3.2. The coating on the inside of both the spherical and conical part of the cavity is involved. The cavity is losing energy by radiation, producing a smaller elevation of the temperature inside the cavity, for all cases. In addition, COMSOL's multiphysics module Heat Transfer with Surface-to-Surface Radiation is needed to combine the Heat Transfer in Solids and Surface-to-Surface Radiation interfaces. Since in this section, we are only interested in the thermal non-uniformity inside the cavity, and since the non-uniformity is not affected by the use of the Surface-to-Surface Radiation module, we use the results without the involvement of this module.

From Figure 6, and considering an initial temperature of $293.15 \mathrm{~K}$, the minimum and maximum temperatures inside the cavity when considering optical heating are respectively $T_{\min }=294.392 \mathrm{~K}$ and $T_{\max }=294.505 \mathrm{~K}$, corresponding to a spatial non-uniformity of $9.1 \%$. In the case of electrical heating, the minimum and maximum temperatures are respectively $T_{\min }=294.392 \mathrm{~K}$, and $T_{\max }=294.460 \mathrm{~K}$, 
corresponding to a non-uniformity of $5.5 \%$. When using the electrical substitution principle, the largest temperature difference between optical and electrical heating equals $45 \mathrm{mK}(=1355 \mathrm{mK}-1310 \mathrm{mK})$, which is found at the top of the sphere (Figure 7). Using the same power for the optical and electrical heating gives the same $T_{\min }$ (Figure 8 ).

\subsubsection{Simulating Earth's Radiation}

A similar procedure as above was applied for the Earth's radiation. The optical heating was determined by simulating the incoming Earth's radiation in the cavity, as a Gaussian beam illumination [34], which approximates the decrease of the irradiance towards the edges considering that the Earth is seen as a Lambertian emitter [38] with a decreasing irradiance towards the limbs. The beam optical power equals $7 \mathrm{~mW}$, considering a maximal terrestrial flux of $340 \mathrm{~W} / \mathrm{m}^{2}$ (Figure 1 ) passing through an aperture of $5 \mathrm{~mm}$ diameter (Figure 4). For the electrical heating, the same power of $7 \mathrm{~mW}$ is used. Figure 9 shows the temperature distributions when simulating the optical heating (left) and electrical heating (right), while Figure 10 (left) shows a comparison between the optical and electrical heating along the spherical part of the cavity, passing through the top of the cavity, indicating a smaller difference than in the case of the Solar radiation. Along the edge of the spherical part of the cavity (Figure 10, right), only a minor difference between the optical and electrical heating can be observed, similar to the Solar case.
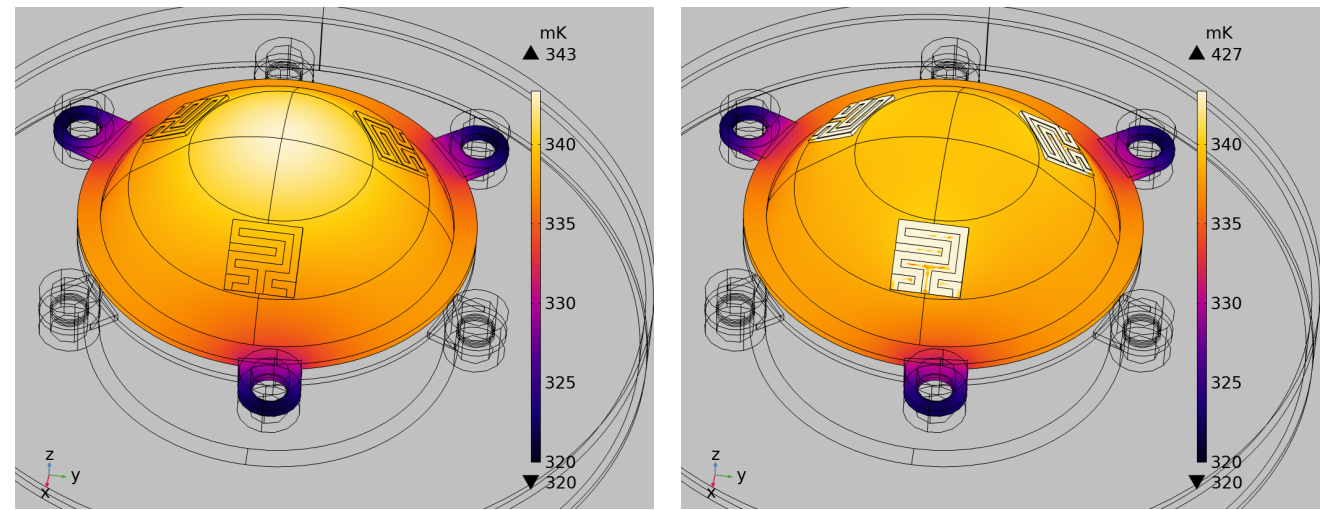

Figure 9. Temperature distribution in the whole cavity, with simulated Earth's radiation by optical heating (left) and by electrical heating (right), with the same power of $7 \mathrm{~mW}$.
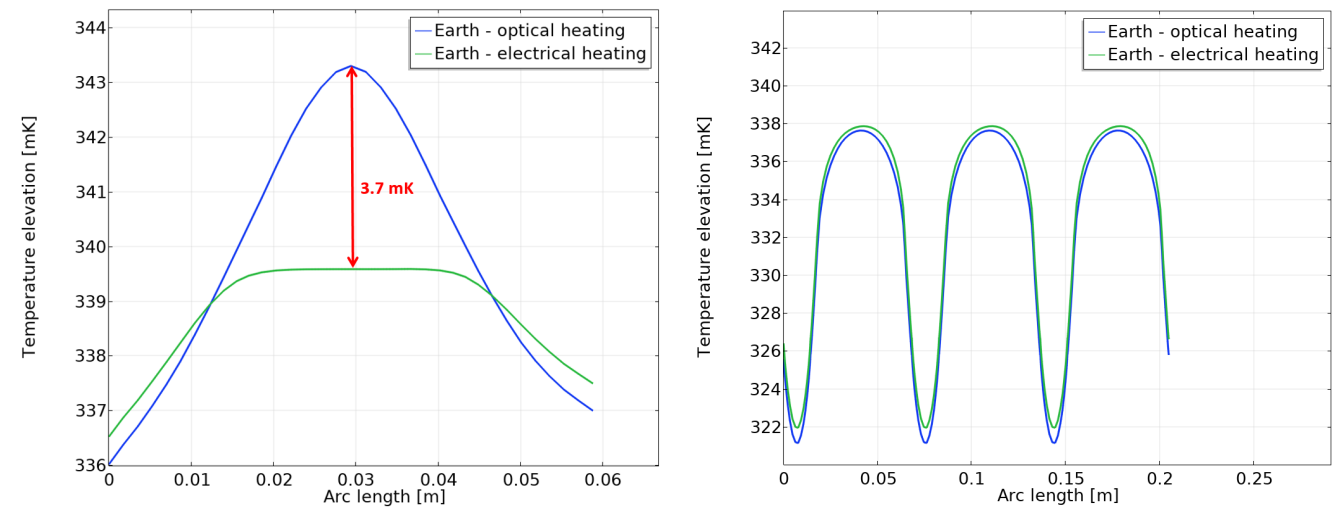

Figure 10. Temperature distribution along the spherical part of the cavity with simulated Earth's radiation, passing through the top of the cavity (left) and along the three heat sinks of the cavity (right), for both optical and electrical heating.

Similar to the Solar case, the largest temperature difference between optical and electrical heating is found at the top of the spherical part, and equals $3.7 \mathrm{mK}(=343.3 \mathrm{mK}-339.6 \mathrm{mK})$. However, in comparison to the Solar case, the temperature distribution of the optical heating shows a higher 
uniformity (Figure 10). Considering a boundary temperature of $293.15 \mathrm{~K}$, the optical heating induces a minimal and maximal cavity temperature of $T_{\min }=293.471 \mathrm{~K}$ and $T_{\max }=293.493 \mathrm{~K}$ respectively, corresponding to a spatial non-uniformity of $6.9 \%$. In the case of the simulated electrical heating, the minimal and maximal cavity temperature equals $T_{\min }=293.471 \mathrm{~K}$ and $T_{\max }=293.49 \mathrm{~K}$ respectively, corresponding to a spatial non-uniformity of $5.9 \%$.

The results of the thermal simulations are summarised in Table 5. It gives, for each of the simulation cases, the electrical power used to heat up the cavity $(P)$, the mean temperature difference between the three thermal sinks and the housing $\left(\Delta T_{\text {sinks }}\right)$, and the temperature difference between the top of the cavity $\left(\Delta T_{\text {top }}\right)$ and the housing. The external thermal conductance $G_{e x t}$ is defined as $\frac{P}{\Delta T_{\text {sinks }}}$. The internal thermal conductance $G_{i n t}$ is defined as $\frac{P}{\left(\Delta T_{t o p}-\Delta T_{\text {sinks }}\right)}$. The thermal non-uniformity within the cavity is defined as:

$$
\frac{\Delta T_{\text {top }}-\Delta T_{\text {sinks }}}{\Delta T_{\text {sinks }}}=\frac{\left(T_{\text {top }}-T_{\text {housing }}\right)-\left(T_{\text {sinks }}-T_{\text {housing }}\right)}{T_{\text {sinks }}-T_{\text {housing }}}=\frac{T_{\text {top }}-T_{\text {sinks }}}{T_{\text {sinks }}-T_{\text {housing }}}=\frac{G_{\text {int }}}{G_{\text {ext }}} .
$$

Table 5. Thermal simulation results for the different heating cases.

\begin{tabular}{ccccc}
\hline Heating Case & $\boldsymbol{P}[\mathrm{mW}]$ & $\Delta T_{\text {sinks }}[\mathrm{mK}]$ & $\Delta T_{\text {top }}[\mathrm{mK}]$ & $G_{\text {int }} / G_{\text {ext }}$ \\
\hline Solar-optical & 27 & 1242 & 1355 & 0.091 \\
Solar-electrical & 27 & 1242 & 1310 & 0.055 \\
Earth-optical & 7 & 321 & 343 & 0.069 \\
Earth-electrical & 7 & 321 & 343 & 0.059 \\
\hline
\end{tabular}

\subsection{Dynamic Performance}

Incoming radiative power enters the cavity when the shutter is opened. In order to make a measurement, thermal equilibrium needs to be reached first, after which the shutter can be closed and the electrical substitution can be performed [39]. Thermal equilibrium can be reached faster by using a servo system, with a performance that depends on its gain. The higher the gain, the faster the thermal equilibrium is reached, but the more thermal noise is present in the radiometer measurements.

We simulated the dynamic thermal behavior of the cavity, the servo system and the shutter operation using an in-house developed program. A servo gain $K_{p}=1000$ is set. A thermal resistor of $40 \mathrm{~K} / \mathrm{W}$ and a temperature difference set-point between the cavity and the housing of $1.2 \mathrm{~K}$ are used, yielding a closed shutter electrical power of $\frac{1.2 \mathrm{~K}}{40 \mathrm{~K} / \mathrm{W}}=30 \mathrm{~mW}$. This closed electrical power corresponds to the maximum optical power that can be measured and is chosen to be slightly larger than the Solar power of $27 \mathrm{~mW}$. The simulation starts with a closed shutter. After $500 \mathrm{~s}$, the shutter starts to alternately open and close with a period of $180 \mathrm{~s}$. An optical power of $7 \mathrm{~mW}$, corresponding to the average Earth radiative power, is applied. Figure 11 shows the time evolution of the temperature error $\Delta$ at the entrance of the servo system in purple and the electrical power $P_{e l}$ in green.

Figure 11 shows that after $500 \mathrm{~s}$, the cavity has not yet reached a thermal equilibrium, as the temperature difference at the entrance of the servo system shows a slow thermal drift with a time constant that is exceeding the shutter period. Nevertheless, it can be observed that the electrical power $P_{e l}$ is not sensitive to this slow thermal drift, as $P_{e l}$ varies correctly between the closed electrical power of $30 \mathrm{~mW}$ and the open electrical power of $30 \mathrm{~mW}-7 \mathrm{~mW}$. The total (optical plus electrical) heating is sustained continuously. During the closed shutter phase lasting $60 \mathrm{~s}$, the optical power is zero and the electrical power is maximum. During the open shutter phase lasting also $60 \mathrm{~s}$, the electrical power will drop to compensate for the non-zero optical power. 


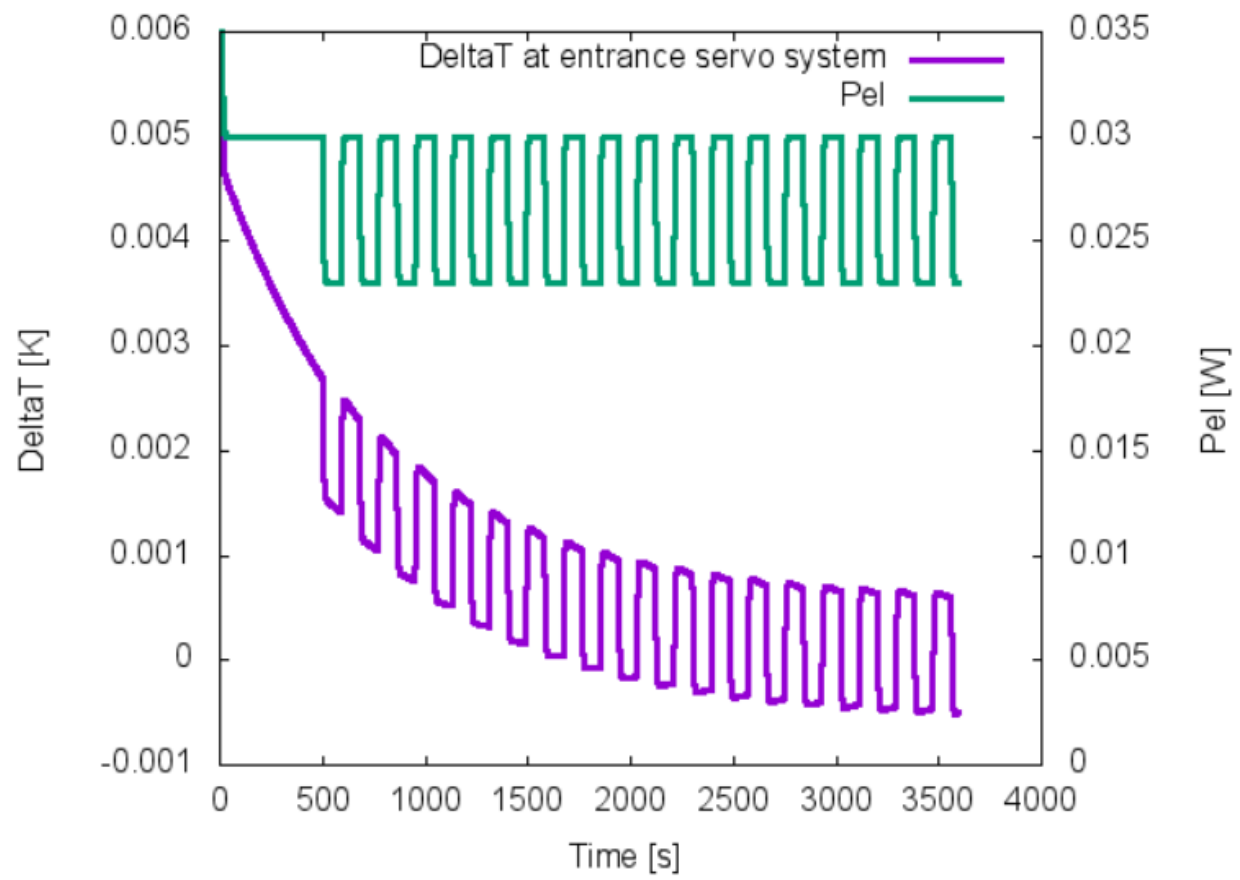

Figure 11. Shuttered servo system, where an optical power of $7 \mathrm{~mW}$ is applied after $500 \mathrm{~s}$. Purple curve, left scale: temporal evolution of the temperature error signal at the entrance of the servo system. Green curve, right scale: temporal evolution of the electrical power.

\subsection{Error Budget}

Different error sources can be considered. These are summarised below. The final error budget is given in Table 6.

1. The thermal uniformity: from the thermal uniformity simulations in Table 5, it is deduced that the location of the electrical resistors can be chosen such that their thermal effect approaches that one of the optical heating caused by a Lambertian source (the Earth) within 0.01 . We expect that this error can be reduced by a factor of 10 by the additional application of pre-flight characterization of the thermal non-uniformity and the in-flight use of the cameras to estimate the angular distribution of the optical radiation (Section 2.3).

2. The cavity absorption: separate cases are considered for Black Velvet and for Vantablack, following Table 3.

3. Aperture area: considering the previously developed RMIB DIARAD TSI radiometers, the aperture area was measured with a relative uncertainty of $200 \mathrm{ppm}$, for a $1 \mathrm{~cm}$ diameter aperture. We assume that we can achieve the same absolute accuracy for a $5 \mathrm{~mm}$ diameter aperture, resulting in an 800 ppm error.

4. Electrical power: based on the experience with the RMIB DIARAD TSI radiometers, we assume that the electrical power can be measured with a relative uncertainty of $100 \mathrm{ppm}$.

The dominant error sources are introduced by the thermal non-uniformity and the aperture area measurement. Rounded to two digits, the use of Vantablack does not improve the accuracy compared to Black Velvet. The estimated absolute accuracy of our radiometer is $0.44 \mathrm{~W} / \mathrm{m}^{2}$. 
Table 6. Error budget. Relative errors have been calculated in the previous sub-sections. The error is relative to the total Earth's outgoing radiative flux $\left(340 \mathrm{~W} / \mathrm{m}^{2}\right.$, Figure 1$)$.

\begin{tabular}{ccc}
\hline Error Sources & Relative & $\mathrm{W} / \mathbf{m}^{2}$ \\
\hline Thermal uniformity & 0.001 & 0.34 \\
Cavity Absorption-Black Velvet & 0.00015 & 0.051 \\
Cavity Absorption-Vantablack & 0.000006 & 0.0016 \\
Aperture area & 0.0008 & 0.272 \\
Electrical power & 0.0001 & 0.0 .034 \\
\hline Total Root Sum Square (RSS) Black Velvet & 0.0013 & 0.44 \\
Total RSS Vantablack & 0.0013 & 0.44 \\
\hline
\end{tabular}

\section{Discussion}

We have introduced a novel wide field-of-view radiometer design, with an anticipated 10-fold improvement of the accuracy in comparison to state-of-the-art WFOV radiometers.

In order to monitor the total Earth's radiative flux from space, the radiometer requires a large FOV of $135^{\circ}$, which is implemented by using a baffle and a precision aperture. The cavity is composed of a conical part with the same top-angle as the FOV, and a spherical part on which the first absorption of the incident optical power occurs. The spherical and conical parts of the cavity are separated by a spacing, such that in flight, the reflection on the spherical part can be measured. Both parts are coated on the inside, allowing the radiative energy to be absorbed and measured by the radiometer. Two types of black coating have been considered: (1) Black Velvet resulting in a cavity absorption factor of 0.99985 , and (2) Vantablack resulting in a cavity absorption factor of 0.999996 . The cavity is put in a housing kept at a constant temperature. Additional electrical power is needed to keep the housing temperature constant. We estimate the total needed power per radiometer unit is $2 \mathrm{~W}$ including $20 \%$ margin. Both parts of the cavity are connected separately to the housing using Permaglas ${ }^{\circledR}$ insulators, with a nominal total thermal resistance of $40 \mathrm{~K} / \mathrm{W}$. On the outside of the spherical part, three electrical resistors are placed symmetrically in order to heat up the cavity for the electrical substitution process.

A major problem of the previous-generation wide field-of-view radiometers is the slowly varying offset of the instrument due to thermal drifts [8]. To solve this issue, we have proposed to use a shuttered operation, which is a proven concept in TSI radiometers. Incoming radiative power is measured by the electrical substitution principle when the shutter is open. The shutter remains open until a thermal equilibrium is reached in the cavity and the electrical substitution can be performed. To limit the measurement time, a servo system with a sufficiently high gain is introduced, which increases the speed with which the thermal equilibrium can be reached. The simulations show that a servo gain of $K_{p}=1000$ allows the system to reach an equilibrium after $90 \mathrm{~s}$. In addition, the shuttered operation allows us to avoid the thermal offset problem. To minimize temperature variations of the shutter, special care will be taken to avoid that it heats up in hot orbits and cools down in cold orbits [40]. If the shutter temperature changes while it is closed, re-radiation into the cavity produces a false time-varying signal, inducing large measurement errors. To avoid this error, following features will be added to the design: (1) thermally isolating the top and the bottom of the shutter, (2) covering the top of the shutter with a reflective coating, and (3) covering the bottom of the shutter with a low emissivity coating [39].

We have simulated the temperature distribution inside the cavity radiometer, in order to assess the spatial non-uniformity. This spatial non-uniformity depends on the spatial distribution of the power used to heat up the cavity. When the cavity is heated up by an incoming radiative power, this power is deposited in the center of the spherical part of the cavity, with a radius dependent on the source (Sun or Earth). In our simulations, the Solar heating near the top of the cavity resulted in a thermal non-uniformity of $9 \%$, while the more evenly spread Earth heating resulted in a thermal non-uniformity of $6 \%$. In the case of the electrical heating, three resistors positioned at the outside part of the cavity are heating up the cavity. By varying the relative height at which the electrical 
resistors are located, the non-uniformity of the electrical heating can be optimized, resulting in a thermal non-uniformity of $5 \%$ according to our simulations. The effect of the thermal gradients within the cavity will, however, be minimized by using the mean measured temperature of the three thermal thermal sinks as input for the servo system. Consequently, we expect an upper limit of 0.01 for the error on the measured power for the stand-alone radiometer, due to the thermal non-uniformity effect. By applying an additional pre-flight characterization of the spatial non-uniformity and the in-flight measurement of the angular distribution of the incoming radiation, we assume that this error can be further reduced to 0.001 . Our error budget indicates the spatial non-uniformity error as the largest error source. More detailed simulations on the dynamic interaction between the thermal non-uniformity and the shuttered servo operation are needed to improve the knowledge of this error source. A second major dominating error source is the aperture area measurement. Compared to these large error sources, the differences in the cavity absorption factor between Black Velvet and Vantablack become negligible. This favors the use of Black Velvet, which has a long history of application in the RMIB TSI space radiometers, which is reproducible and more easily applicable than Vantablack [16].

\section{Conclusions}

Climate change is provoked by the fact that the net Earth's energy budget is non-zero. For this reason, measuring the Earth's Radiation Budget and the Earth Energy Imbalance is of fundamental importance, requiring the measurement of both the Total Solar Irradiance and Earth's Total Outgoing Radiation. It is recommended that critical climate variables like the Earth Radiation Budget are monitored by at least two different types of instruments, and are analyzed by at least two independent science teams [14]. Therefore, we propose the development of novel space instrumentation, offering an alternative measurement of the Earth Radiation Budget, targeting an absolute accuracy of $1 \mathrm{~W} / \mathrm{m}^{2}$ and target stability of $0.1 \mathrm{~W} / \mathrm{m}^{2}$ per decade, while being independently developed from the NASA's CERES mission. More specifically, we propose a novel wide field-of-view radiometer design, aiming to minimize the spatial thermal non-uniformity inside the cavity. In order to perform the most accurate measurements, our radiometer uses: (1) a novel cavity shape, (2) a precision aperture, (3) the use of a servo system, (4) a dual-channel radiometer, (5) a shutter for each cavity. The shuttered operation allows us to avoid the thermal offset issue, which is encountered in the current state-of-the-art wide field-of-view radiometers [8]. The estimated accuracy of our radiometer is $0.44 \mathrm{~W} / \mathrm{m}^{2}$ for the measurement of Earth's outgoing radiation. This is a considerable improvement by an order of magnitude compared to the state-of-the-art of $4.9 \mathrm{~W} / \mathrm{m}^{2}$ [1].

Since the simulations show promising results towards the measurement of the Earth Radiation Budget and Earth Energy Imbalance with an improved accuracy, a prototype of this radiometer will be built and characterized. In addition to this radiometer, two wide field-of-view cameras will be added to increase the accuracy and spatial resolution of the wide field-of-view radiometer measurements. To distinguish the reflected Solar radiation from the emitted terrestrial thermal radiation, while observing the Earth, one camera will operate between 400 and $900 \mathrm{~nm}$, while the other will operate between 8 and $14 \mu \mathrm{m}$. The accuracy will be increased by the characterization of the angular distribution of the radiation entering the wide field-of-view radiometer, while the increased spatial resolution of the measurements will allow to discriminate cloudy from clear-sky scenes, as well as to estimate the aerosol load for clear-sky scenes. The design of these cameras will be the subject of future studies.

Author Contributions: L.S. (Luca Schifano) has conducted this study, including methodology, formal analysis and investigation. T.G. has helped with COMSOL Multiphysics simulations, and S.D. with the in-house developed program in C language. L.S. (Lien Smeesters), S.D. and F.B. have ensured the supervision. S.D. is reponsible for funding acquisition. L.S. (Luca Schifano) has written the original draft. All co-authors have participated with the review and editing. All authors have read and agree to the published version of the manuscript.

Funding: This research was funded by the Solar-Terrestrial Center of Excellence (STCE). 
Acknowledgments: B-PHOT acknowledges the Vrije Universiteit Brussel's Methusalem foundations as well as the Hercules Programme of the Research Foundation Flanders (FWO).

Conflicts of Interest: The authors declare no conflict of interest.

\section{Abbreviations}

The following abbreviations are used in this manuscript:

$\begin{array}{ll}\text { ADC } & \text { Analog-to-Digital Converter } \\ \text { CERES } & \text { Clouds and the Earth's Radiant Energy System } \\ \text { DAC } & \text { Digital-to-Analog Converter } \\ \text { DIARAD } & \text { Differential Absolute Radiometer } \\ \text { ECV } & \text { Essential Climate Variable } \\ \text { EEI } & \text { Earth Energy Imbalance } \\ \text { ERB } & \text { Earth Radiation Budget } \\ \text { ERBE } & \text { Earth Radiation Budget Experiment } \\ \text { FWO } & \text { Research Foundation Flanders } \\ \text { GCOS } & \text { Global Climate Observing System } \\ \text { ISR } & \text { Incoming Solar Radiation } \\ \text { LTAN } & \text { Local Time of Ascending Node } \\ \text { LTDN } & \text { Local Time of Descending Node } \\ \text { LW } & \text { LongWave } \\ \text { NASA } & \text { National Aeronautics and Space Administration } \\ \text { NOAA } & \text { National Oceanic and Atmospheric Administration } \\ \text { NPP } & \text { National Polar-orbiting Partnership } \\ \text { OLR } & \text { Outgoing Longwave Radiation } \\ \text { RAVAN } & \text { Radiometer Assessment using Vertically Aligned Nanotubes } \\ \text { RMIB } & \text { Royal Meteorological Institute of Belgium } \\ \text { RSR } & \text { Reflected Solar Radiation } \\ \text { RSS } & \text { Root Sum Square } \\ \text { SIMBA } & \text { Sun-earth IMBAlance } \\ \text { SPI } & \text { Serial Peripheral Interface } \\ \text { STCE } & \text { Solar-Terrestrial Center of Excellence } \\ \text { SW } & \text { ShortWave } \\ \text { TOA } & \text { Top Of Atmosphere } \\ \text { TOR } & \text { Total Outgoing Radiation } \\ \text { TSI } & \text { Total Solar Irradiance } \\ \text { VACNT } & \text { Vacuum Aligned Carbon NanoTubes } \\ \text { WMO } & \text { World Meteorological Organization } \\ \text { WFOV } & \text { Wide field-of-view } \\ & \end{array}$

\section{References}

1. Dewitte, S.; Clerbaux, N. Measurement of the Earth Radiation Budget at the Top of the Atmosphere-A Review. Remote Sens. 2017, 9, 1143. [CrossRef]

2. World Meteorological Organization. GCOS Implementation Plan. 2016. Available online: https:// unfccc. int/sites/default/files/gcos_ip_10oct2016.pdf (accessed on 18 December 2019).

3. Hansen, J.; Sato, M.; Kharecha, P.; von Schuckmann, K. Earth's energy imbalance and implications. Atmos. Chem. Phys. 2011, 11, 13421-13449. [CrossRef]

4. Von Schuckmann, K.; Palmer, M.; Trenberth, K.; Cazenave, A.; Chambers, D.; Champollion, N.; Hansen, J.; Josey, S.; Loeb, N.; Mathieu, P.; et al. An imperative to monitor Earth's energy imbalance. Nature Clim. Chang. 2016, 6, 138-144. [CrossRef]

5. Dewitte, S.; Clerbaux, N.; Cornelis, J. Decadal Changes of the Reflected Solar Radiation and the Earth Energy Imbalance. Remote Sens. 2019,11, 663. [CrossRef] 
6. Johnson, G.; Lyman, J.; Loeb, N. Improving estimates of Earth's energy imbalance. Nature Clim. Chang. 2016, 7, 639-640. [CrossRef]

7. Trenberth, K.; Fasullo, J.; von Schuckmann, K.; Cheng, L. Insights into Earth's Energy Imbalance from Multiple Sources. J. Clim. 2016, 29, 7495-7505. [CrossRef]

8. Wong, T.; Smith, G L.; Kato, S.; Loeb, N.; Kopp, G.; Shrestha, A. On the Lessons Learned From the Operations of the ERBE Nonscanner Instrument in Space and the Production of the Nonscanner TOA Radiation Budget Data Set. IEEE Trans. Geosci. Remote Sens. 2018, 10, 5936-5947. [CrossRef]

9. Palmer, M. Reconciling estimates of ocean heating and Earth's radiation budget. Curr. Clim. Chang. Rep. 2017,1, 78-86. [CrossRef]

10. Loeb, N.; Wielicki, B.; Doelling, D.; Smith, G L.; Keyes, D.; Kato, S.; Manalo-Smith, N.; Wong, T. Toward optimal closure of the Earth's top-of-atmosphere radiation budget. J. Clim. 2009, 22, 748-766. [CrossRef]

11. Earth Venture Continuity Radiation Budget Science Working Group. Measurement and Instrument requirement recommendations for an Earth Venture Continuity Earth Radiation Budget instrument. 2018. Available online: https://smd-prod.s3.amazonaws.com/science-pink/s3fs-public/atoms/files/ERB_SWG_ Rept_Draft_07242018_TAGGED.pdf (accessed on 18 December 2019).

12. Wielicki, B.; Barkstrom, B.; Harrison, E.; Lee, R., III; Smith, G.L.; Cooper, J. Clouds and the Earth's Radiant Energy System (CERES): An Earth Observing System Experiment. Bull. Am. Meteorol. Soc. 1996, 77, 853-868. [CrossRef]

13. Barkstrom, B. The Earth Radiation Budget Experiment. Bull. Am. Meteorol. Soc. 1984, 5, 1170-1185. [CrossRef]

14. Ohring, G.; Wielicki, B.; Spencer, R.; Emery, B.; Datla, R. Satellite Instrument calibration for measuring global climate change. Bull. Am. Meteorol. Soc. 2005. [CrossRef]

15. Crommelynck, D.; Domingo, V. Solar irradiance observations. Science 1984, 225, 180-181. [CrossRef] [PubMed]

16. Swartz, W.; Lorentz, R.; Papadakis, S.; Huang, P.; Smith, A.; Deglau, D.; Yu, Y.; Reilly, S.; Reilly, N.; Anderson, D. RAVAN: CubeSat demonstration for multi-point Earth Radiation Budget measurements. Remote Sens. 2019, 7, 796. [CrossRef] [PubMed]

17. Dewitte, S.; Chevalier, A.; Meftah, M.; Kerschen, G.; Karatekin, O. The Sun-earth Imbalance radiometer for a direct measurement of the net heating of the Earth. In Proceedings of the 4 S Symposium 2014, Majorca, Spain, 26-30 May 2014.

18. Royal Meteorological Institute of Belgium, SIMBA CubeSat. Available online: https://www.meteo.be/fr/ infos/actualite/le-satellite-simba-est-pret-a-etre-lance (accessed on 5 December 2019).

19. Loeb, N.; Kato, S. Angular Distribution Models for Top-of-Atmosphere Radiative Flux Estimation from the Clouds and the Earth's Radiant Energy System Instrument on the Terra Satellite. Part I: Methodology. J. Atmos. Ocean. Technol. 2005, 4, 338-351. [CrossRef]

20. Dewitte, S.; Karatekin, O.; Chevalier, A.; Clerbaux, N.; Meftah, M.; Irbah, A.; Delabie, T. The Sun-Earth Imbalance radiometer for a direct measurement of the net heating of the Earth. Geophys. Res. Abstr. 2015, 17, EGU2015-15259-1.

21. Dewitte, S.; Nevens, S. The Total Solar Irradiance Climate Data Record. Astrophys. J. 2016, 830, 25. [CrossRef]

22. Willson, R. Active Cavity Radiometer. Sol. Phys. 1980, 1, 109. [CrossRef]

23. Kim, G.J.; Yoo, Y.S.; Kim, B.H.; Lim, S.D.; Hyun Song, J. A small-size transfer blackbody cavity for calibration of infrared ear thermometers. Physiol. Meas. 2014, 35, 753-762. [CrossRef]

24. Adibekyan, A.; Kononogova, E.; Monte, C.; Hollandt, J. High-Accuracy Emissivity Data on the Coatings Nextel 811-21, Herberts 1534, Aeroglaze Z306 and Acktar Fractal Black. Int. J. Thermophys. 2017, $38,89$. [CrossRef]

25. Dury, M.; Theocharous T.; Harrison, N.; Fox N.; Hilton, M. Common black coatings - reflectance and ageing characteristics in the 0.32-14.3 $\mu$ wavelength range. Opt. Commun. 2007, 2, 262-272. [CrossRef]

26. Tomlin, N.; Curtin, A.; White, M.; Lehman, J. Decrease in reflectance of vertically-aligned carbon nanotubes after oxygen plasma treatment. Carbon 2014, 74, 329-332. [CrossRef]

27. Kopp, G.; Lawrence, G. The Total Irradiance Monitor (TIM): Instrument Design. Sol. Phys. 2005, 1, 91-109. [CrossRef]

28. Crommelynck, D.; Dewitte, S. Metrology of total solar irradiance monitoring. Adv. Space Res. 1999, 2, $195-204$. [CrossRef] 
29. Dewitte, S.; Gonzalez, L.; Clerbaux, N.; Ipe, A.; Bertrand, C.; De Paepe, B. The Geostationary Earth Radiation Budget Edition 1 data processing algorithms. Adv. Space Res. 2008, 11, 1906-1913. [CrossRef]

30. Surrey NanoSystems Ltd, Vantablack S-VIS Datasheet. Available online: https:/ /www.surreynanosystems. com/assets/media/vantablack-s-vis-a4-data-sheet-automotive-v009-reduced.pdf (accessed on 18 December 2019).

31. Surrey NanoSystems Ltd, Vantablack S-IR Datasheet. Available online: https://www.surreynanosystems. com/assets/media/vantablack-s-ir-space-a4-data-brochure-2019-v019.pdf (accessed on 18 December 2019).

32. Buschman, A.; Pittman, C. Configuration Factors for Exchange of Radiant Energy between Axisymmetrical Sections of Cylinders, Cones, and Hemispheres and Their Bases. NASA Technical Note D-944. 1961. Available online: https://ntrs.nasa.gov/archive/nasa/casi.ntrs.nasa.gov/19980227400.pdf (accessed on 18 December 2019).

33. Naraghi, M.; Warna, J. Radiation configuration factors from axisymmetric bodies to plane surfaces. Int. J. Heat Mass Transf. 1988,7, 1537-1539. [CrossRef]

34. COMSOL Multiphysics, Heat Transfer Module User's Guide, Version 5.4. 2018. Available online: https: //doc.comsol.com/5.4/doc/com.comsol.help.heat/HeatTransferModuleUsersGuide.pdf (accessed on 18 December 2019).

35. Pryor, R. Multiphysics Modeling using Comsol 4: A first principles approach. In Mercury Learning and Information; Jones and Bartlett Publishers: Sudbury, MA, USA, 2012.

36. Innovation Development Materials Composites, PERMAGLAS ME771. Available online: http://www. idmcomposites.com/fichiers/permaglas-me771-en_75.pdf (accessed on 18 December 2019).

37. Van Eck, R.; Klep, M.; van Schijndel, J. Surface to Surface Radiation Benchmarks. In Proceedings of the 2016 COMSOL Conference, Munich, Germany, 12-14 October 2016.

38. Tu, L.; Qin, Z.; Yang, L.; Wang, F.; Geng, J.; Zhao, S. Identifying the Lambertian Property of Ground Surfaces in the Thermal Infrared Region via Field Experiments. Remote Sens. 2017, 9, 481. [CrossRef]

39. Mekaoui, S.; Dewitte, S.; Conscience, C.; Chevalier, A. Total solar irradiance absolute level from DIARAD/SOVIM on the International Space Station. Adv. Space Res. 2010, 45 1393-1406. [CrossRef]

40. Dewitte S.; Helizon, R.; Wilson, R. Contribution of the Solar Constant (SOLCON) program to the long-term total solar irradiance observations. J. Geophys. Res. Atmos. 2001, 106, 15759-15766. [CrossRef]

(C) 2020 by the authors. Licensee MDPI, Basel, Switzerland. This article is an open access article distributed under the terms and conditions of the Creative Commons Attribution (CC BY) license (http://creativecommons.org/licenses/by/4.0/). 